\title{
ERRATUM
}

Maria-Alexandra Georgopoulos •

Apostolos P. Georgopoulos • Nicole Kurz •

Barbara Landau

\section{Figure copying in Williams syndrome and normal subjects}

Published online: 6 August 2004

(C) Springer-Verlag 2004

\section{Exp Brain Res (2004) 157:137-146}

The last name of the third author was misspelled. The correct name is as follows: Nicole Kurz.

The online version of the original article can be found at http://dx. doi.org/10.1007/s00221-004-1834-0

M.-A. Georgopoulos

Brain Sciences Center, Minneapolis Veterans Affairs Medical Center,

Minneapolis, MN, USA

M.-A. Georgopoulos

Department of Radiology, University of Minnesota Medical

School,

Minneapolis, MN, USA

\section{A. P. Georgopoulos}

Departments of Neuroscience, Neurology and Psychiatry,

University of Minnesota Medical School,

Minneapolis, MN, USA

A. P. Georgopoulos $(\square)$

Brain Sciences Center (11B), VAMC,

One Veterans Drive,

Minneapolis, MN 55417, USA

e-mail: omega@umn.edu

Tel.: +1-612-7252282

Fax: +1-612-7252291

N. Kurz

Department of Psychology, University of Delaware,

Newark, DE, USA

B. Landau

Department of Cognitive Science, Johns Hopkins University,

Baltimore, MD, USA 